$\xi=-$ 国

\title{
Evaluation of Performance of Flux Switching Motor in Segmented Rotor Using Permanent Magnet For Direct Drive
}

\author{
Enwelum I. Mbadiwe1*, Erwan B. Sulaiman² \\ ${ }^{1,2}$ Research Centre for Applied Electromagnetics, \\ Faculty of Electrical/Power Engineering, \\ Universiti Tun Hussein Onn Malaysia. \\ 86400 Parit Raja, Batu Pahat Johor, Malaysia \\ * Corresponding author E-mail: mb.fkee.uthm@gmail.com
}

\begin{abstract}
The torque action provided by combustion engine in conventional vehicles has been boosted by added electric motor, a device which also provide torque, for fuel economy in hybrid electric vehicle. Meanwhile, the complicated nature of combustion engine still poses economic imperatives as petroleum resources are getting depleted. Interestingly, vehicles propelled by electric motor powered by electricity, will completely eliminate combustion engine using fossil oil and also provide clean and reliable vehicles for personal transportation. Since electric motor is a core component, high torque motors are necessary for direct drive application. This papers presents a feasible 24 stator - 10 rotor segments flux switching motor (FSM) using $1 \mathrm{~kg}$ weight of PM. FSM is advance form of synchronous machine with double frequency that locates all active materials on the stator only. Permanent magnet (PM) flux source is chosen because it offers loss free excitation without external circuit connection. The JMAG® Studio tool version 14.1 was employed for 2D- FEA design and performance investigation of motor in terms of cogging torque and average torque. Finally, simulation result of proposed motor successfully achieved $352 \mathrm{Nm}$ and constant power of $36 \mathrm{~kW}$ projecting it as viable candidate for high torque necessary for direct drive application.
\end{abstract}

Keywords: Direct Drive; Flux Switching Motor; High Torque; Permanent Magnet; Segmented Rotor.

\section{Introduction}

Electric motor, a device that provides rotational torque has been developed to boost the torque provided by combustion engine in vehicles for effective operation, thus hybrid electric vehicle. In fact, manufacturing of combustion engines remains complicated and petroleum resources are nearing depletion which renders hybrid electric vehicles no longer useful in the days ahead. This background highlights replacing the combustion engine in both conventional vehicles and hybrid electric vehicle with a high torque electric motor, thus full electric vehicle which is independent of petroleum oil, as a reliable means of road transportation.

Two and three wheeled vehicles, particularly, motorcycles and scooters in the automotive sector, have been equipped with combustion engines that require fossil oil fired in its chamber, to create torque action for propulsion. This engine has dominated all manner of automobiles application for over ten decades already [1-5]. Along the line, cost of fuel started to rise up and the need for fuel economy became necessary for everyone. For this reason, hybrid electric scooter was developed [6-9]. Hybrid electric vehicles are automobiles using equipped with combustion engine using fossil oil and electric motor together, for propulsion drive [10-13].

Electric motor consists of two major components with magnetic coupling, receives input electrical quantities of voltage and current for mechanical output torque and speed $[14,15]$. Since electric motor also provides torque for propulsion and the core component for this application, few electric motors have been developed that successfully assisted to achieve fuel economy while operating at different torque capabilities [16-18]. These motors are induction motor (IM), permanent magnet direct current motor (PMDC), switched reluctance motor (SRM) and interior permanent magnet synchronous motor (IPMSM). In assessment, IM has low maintenance cost and also functions in hostile environments, but it has quite low efficiency with low speed light region, inferior starting torque, high power factor and speed which cannot be easily changed $[16,19]$. The PMDC has simple control, high efficiency, but has problems of commutator with regular servicing of brushes. For, SRM, it has long constant power range but its performance is characterized by acoustic noise, torque ripple, bus current ripple and electromagnetic interference [15, 20, 21]. For IPMSM, it has high torque density and power density, but has a complex design structure because permanent magnets (PMs) are inserted inside the rotor with assembly lacking mechanical strength and limiting motor performance at high temperature condition $[16,21]$.

Moreover, the hybrid excitation flux switching motor (HEFSM) $[10,17]$ was developed to overcome the disadvantages of former motors in terms of copper loss reduction, simple shape to ease design enhancement for improved torque with less permanent magnet volume usage $[17,23]$. While, HEFSM was able to manage magnet temperature rise, it has numerous disadvantages namely; complicated design structure, requires external circuit connections for secondary excitation, reduced slot area and low over-load capability resulting from heavy saturation [24-27]. Meanwhile, all these electric motors are inner rotor [8-13, 18-26].

Figure 1 illustrates cross sections of designed electric motors for hybrid electric vehicle application. 

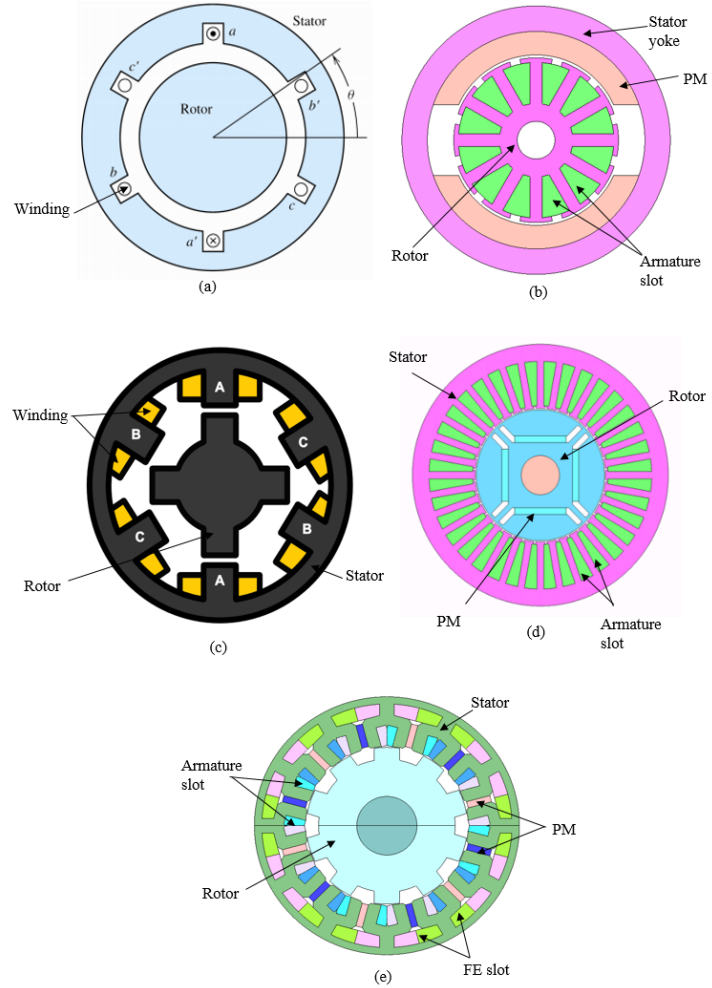

Fig. 1: Cross-sections of electric motors for hybrid application (a) Induction motor (IM) (b) Permanent magnet direct current (PMDC) (c) Switched reluctance motor (SRM) (d) Interior permanent magnet synchronous motor (IPMSM) (e) Hybrid excitation flux switching motor (HEFSM)

Utilizing both combustion engine and electric motor have obtained a wide-range of high fuel efficiency in hybrid scooter, but the complicated nature and cost of engine still remains financial burden to everyone. In addition to this danger, the world's oil production is nearing its peak and depletion is very obvious. Therefore, it is important to eliminate combustion engine, the use of fuel oil and hybrid electric motorcycles and scooters. This sparks the idea of developing full electric scooter propelled by electric motor [8] To transit from hybrid assisted electric motor to a direct-drive application demands rotor being transferred from inner rotor structure to outer rotor structure. More so, the selection of direct-drive and in-wheel motor is very important that requires special attention, especially for long distance travels. In this case, key features are the following; high torque at low speed for starting and climbing, reliability, fast torque response and reasonable cost. Recently, a four-cell stator with rotor mounted permanent magnet (SPMSM) has been developed for electric scooter ES Model 11 for fully electric scooter propulsion [33]. It consists of high permanent magnet volume with all stator teeth winding for the purpose of high torque to sustain acceleration for long distance travels. While this design achieved semi-high torque, assembly lacks mechanical strength at high temperature operation. Figure 2 shows crosssections of SPMSM.

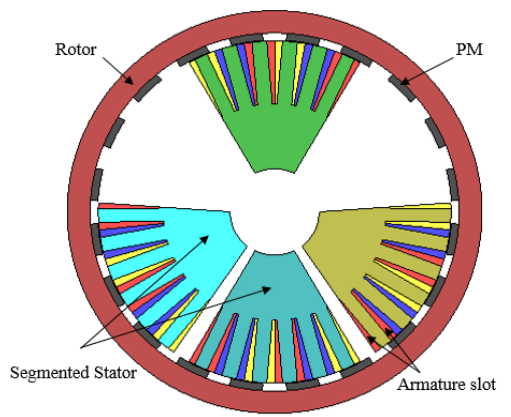

Fig. 2: Cross-sections of three-phase SPMSM
In order to avoid the disadvantages inherited by SPMSM, research and development continue in the area of improved motor for torque and power to sustain acceleration $[11,28]$. This led to development of flux switching motor (FSM) in the 1950s $[29,30]$. FSM is advance form of synchronous machine in which its rotor does not carry any material as all materials are housed on the stator for easy cooling [26,27].

Generally, FSM is designated into three internal kinds such as flux switching motor with PM flux source (PMFSM), flux switching motor with FE source (FEFSM) and hybrid flux switching motor with PM and FE as main and secondary sources $[23,25]$.

The PMFSM has attracted so much interest due to its advantages of loss-free excitation and elimination of connections to external circuit connection, thereby recording less copper loss. This motor has various factors including advances in magnetic material, and computer aided design tools $[10,12]$. With PM being the natural source of flux, various topologies have been designed for numerous allied purposes such as automotive and aerospace. All these designs are with inner rotor structure for out-wheel applications [26-29]. In the same mode, outer rotor PMFSM motor had been proposed for in-wheel [31]. Meanwhile, all the designs mentioned above have so far been in salient rotor pole [1-13]

In this paper, PMFSM employing an unconventional segmented rotor (Segor-PMFSM) is presented for in-wheel application. A research carried out recently showed that the use of segmented rotor ensured excellent torque performance [16]. The use of segmented rotor in flux switching mechanism has the gain of operating with a bipolar flux in the magnetic circuit as bipolar flux linkage is achieved by the rotor from the armature winding [17].

\section{Design Specifications and Electrical Supply Restrictions of Proposed Segor-PMFSM}

Design restrictions and all parameter specifications of the motor understudy are the same with conventional PMSM for electric scooter [15]. Every electrical restriction related with inverter is the same as listed in Table 1. The limit of armature current density is set at $30 \mathrm{~A} / \mathrm{mm}^{2}$ for the armature coil. Diameter of motor and stack length are the same with PMSM installed in eclimo electric scooter. The target torque of the proposed motor is set to be more than $110 \mathrm{Nm}$ with the power more than $6 \mathrm{~kW}$. The rotor structure is segmented and bonded using external shaft. Commercial 2D FEA JMAG® Studio tool package version 14.1 released by Japanese Research Institute (JRI) was used for the design and simulation. The PM material type utilized is Neo-max-35ah having the residual flux density and coercive force at $20^{\circ} \mathrm{C}$ are $1.2 \mathrm{~T}$ and $932 \mathrm{kA} / \mathrm{m}$, the electrical steel $35 \mathrm{~h} 210$ is used for rotor and stator. Additionally, the external rotor shaft is a non-ferromagnetic aluminium offering low weight to secure the isolated segmented rotor members [33].

Meanwhile, electric motors used for vehicular application should have high torque to sustain acceleration for long distance operation. For this reason, the design procedures for the proposed PMFSM has chosen to work on the rotor pole associated with magnetic loading so as to increase its flux profile while every other parameter is kept constant with electrical loading. The effect of pole shaping enhances an increase in torque which will also boost the performance [3-7]. Similarly, consideration was taken to design appropriate rotor segment. Earliest designs were suitable for out-wheel application, thus needed to be completely modified. A recent motor design employing outer rotor was accomplished by compromising an external shaft and this was not ideal for a defined application [32].

To avoid this deficiency by ensuring mechanical retainment, the proposed design attaches external rotor shaft without adding excessive material.

Therefore, the formula in (1) and (2), provide the procedures to accomplish rotor design. 
Rotor angle, $\theta=\frac{360^{\circ} \mathrm{x} \text { rotor tooh width }}{2 \pi x \text { innerrotorradius }}$

Segment span $\theta_{s}=\theta+x$

Where $1^{\mathrm{o}} \leq x \geq 3^{\mathrm{o}}, \mathrm{x}$ in degree

Table 1: Motor Dimension, Parameters Specification and Electrical Supply Restrictions

\begin{tabular}{|c|c|c|}
\hline Parameters & SPMSM & Segor-PMFSM \\
\hline Motor diameter, $D_{e}$ & $297.4 \mathrm{~mm}$ & $297.4 \mathrm{~mm}$ \\
\hline Motor speed, $n_{s}$ & $1900 \mathrm{rpm}$ & $>1900 \mathrm{rpm}$ \\
\hline Phase & 3 & 3 \\
\hline Rotor type & Round & Segmented \\
\hline Rotor pole & 100 & 14 \\
\hline Stator type & Four-cell segment & Salient \\
\hline Stator pole & 24 & 24 \\
\hline PM weight & $1.2 \mathrm{~kg}$ & $1 \mathrm{~kg}$ \\
\hline Stack length, $L_{s t k}$ & 100 & 100 \\
\hline DC input volt & $650 \mathrm{~V}$ & $415 \mathrm{~V}$ \\
\hline Current density & $360 \mathrm{~A}_{\mathrm{rms}}$ & $120 \mathrm{~A}_{\mathrm{rms}}$ \\
\hline Arm. slot area & $432 \mathrm{~mm}{ }^{2}$ & $432 \mathrm{~mm}^{2}$ \\
\hline No. of conductors & 18 & 18 \\
\hline Average torque & $110 \mathrm{Nm}$ & $>>110 \mathrm{Nm}$ \\
\hline Average power & $6 \mathrm{~kW}$ & $>>6 \mathrm{~kW}$ \\
\hline
\end{tabular}

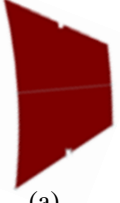

(a)

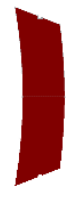

(b)
Fig. 3: Rotor structure (a) Initial design (b) Optimized design

On the rotor segment dimensions such as length, span and width, the width of rotor significantly influences performance which was increased from initial $17.4 \mathrm{~mm}$ to $28.0 \mathrm{~mm}$ to avoid saturation. Using (2), the segment span was adjusted from initial 16 degrees to 20 degrees. Meanwhile, cross-sections of three-phase 24S-10P Segor-PMFSM is shown in Figure 4.

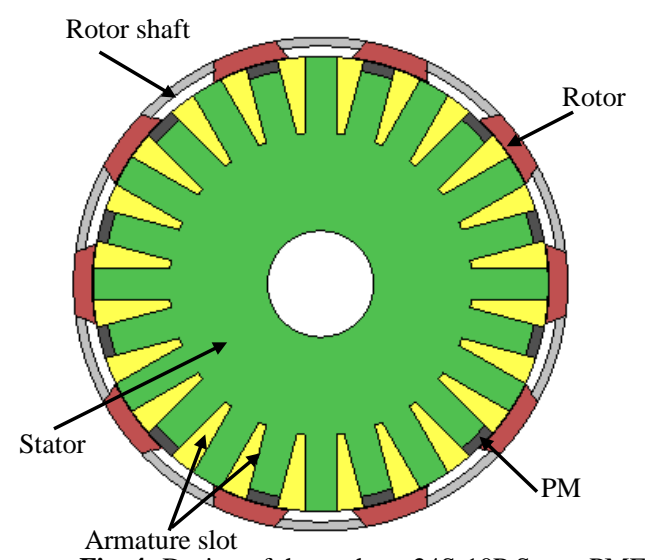

Fig. 4: Design of three-phase 24S-10P Segor-PMFSM

\subsection{The required torque}

In this FSM, both armature and PM are housed on the stator. The PM flux originates from the stator tip, links with the rotor and linking the stator armature winding which changes with rotor position as it changes in amplitude and polarity. The rotation is due to minimizing of opposition force from the power effect of magnetic force between stator PM flux and rotor poles [15-17]. Due to the power effect of reducing the repulsion force of air-gap flux linkage, the rotating field will always be unaligned to the rotating flux to produce torque [15].

Therefore, the flux developed $T_{d}$ of the proposed Segor-PMFSM to air-gap flux linkage, $\phi_{g}$ is given in (3):

Torque developed, $T_{d}=\frac{1}{2} L \phi_{g}{ }^{2}$

Where $L$, is the inductance of the stator winding. Similarly, in the electrical side, torque varies with speed $\omega$ and is peak at low speed under maximum power input, $P_{i n}$ as expressed in (4):

Torque developed, $T_{d}=\frac{P_{i n}}{\omega}$

\subsection{Specific magnetic loading}

This motor design has taken into consideration the material for stator and rotor core as each has peculiar torque density property. Therefore, specific magnetic loading which is the competence of magnetic flux inflow of machine over its entire volume is given in (5)

Specific magnetic loading, $B_{a v}=\frac{P_{s} \phi_{p o}}{\pi D_{e} L_{s t k}}$

Where $D_{e}$ is size of motor, $P_{s}$ is no of stator pole, $\phi_{p o}$ is the flux per pole and $L_{s t k}$ is motor's stack length. More so, comparing the flow of flux around the armature winding in stator and rotor core, air gap flux linkage is very significant in contributing to the rotation and performance of motor. Meanwhile, equivalent magnetic circuit of Segor-PMFSM is illustrated in Fig. 5 and airgap flux linkage is expressed in (6):

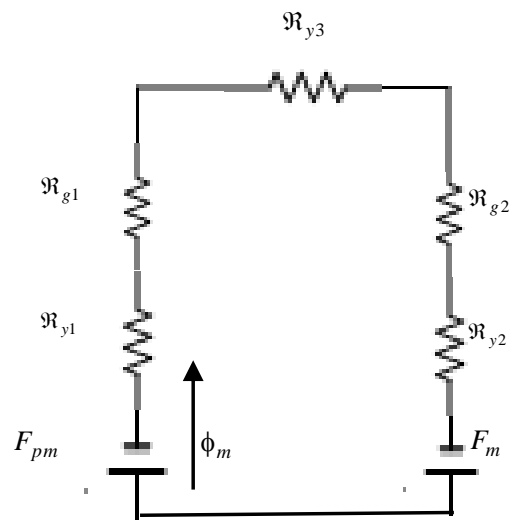

Fig. 5: Equivalent magnetic circuit of Segor-PMFSM

From Figure 5, air-gap flux linkage, $\phi_{m}$ is expressed as presented in (6).

$\phi_{m}=\frac{F_{m}-F_{p m}}{\mathfrak{R}_{y 1}+\mathfrak{R}_{y 2}+\mathfrak{R}_{y 3}+\mathfrak{R}_{g 1}+\mathfrak{R}_{g 2}}$

Where, $F_{m}$ is the MMF force of coil, $F_{p m}$ is the force of PM [Ampere/turn], $\mathfrak{R}_{y 1}, \mathfrak{R}_{y 2}$ are the reluctances of stator yoke, $\mathfrak{R}_{y 3}$ is reluctance of outer rotor, $\mathfrak{R}_{g 1}, \mathfrak{R}_{g 2}$ are the air-gap reluctance of the motor. However, in (6), the force of PM is being subtracted from the MMF of coil as it is in opposite direction. 


\section{Performance analysis}

The performances of the proposed motor in no-load and load considers magnetic flux linkage, cogging torque and induced backemf, while under load condition, torque versus armature current density, torque versus speed characteristics, and average torque and power and efficiency are examined under the following subsections..

\subsection{Magnetic flux linkage and cogging torque}

The three phase flux linkage of the proposed Segor-PMFSM for direct drive is plotted in Figure 6. Obviously, the resulting amplitude of PM flux is $0.1 \mathrm{~Wb}$, capable of high torque. Furthermore, three-phase waveforms are smooth and sinusoidal for motor operation. Cogging torque is the effect of interaction in electric motor between the permanent magnet in stator and rotor. Though it causes noise and vibration, but the machine remains in safe operation when the value of cogging is $10 \%$ of average torque. Moreover, it does not add to electromagnetic output profile, it only affects in torque pulsation. Meanwhile, cogging torque of the proposed motor is $12 \mathrm{Nm}$ peak-to-peak which is low for safe operation. Consequently, the number of periods, $N_{p}$ of cogging torque waveform over a rotation of one stator tooth pitch is expressed in (7) [17].

$$
N_{p}=\frac{N_{r}}{H C F\left[N_{s t}, N_{r}\right]}
$$

Where, $H C F$ is the highest common factor between stator slots $N_{s t}$ and number of rotor poles $N_{r} . N_{p}$ is the electrical angle of rotation, and setting $\alpha_{\text {cogg }}$ for each period of $\operatorname{cog}$ ging torque as

$\alpha_{\operatorname{cogg}}=\frac{360^{\circ}}{N_{p} N_{s t}}$, electrical cycle $N_{\text {elect }}$ is given in (8)

$N_{\text {elect }}=\frac{N_{p} N_{s t}}{N_{r}}$

Furthermore, cogging plot of the proposed Segor-PMFSM is illustrated in Figure 7.

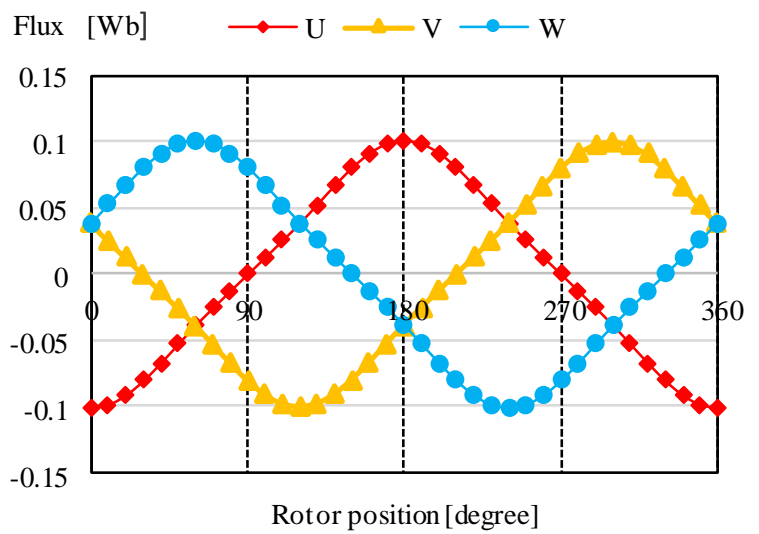

Fig. 6: Three-coil phase flux linkage of Segor-PMFSM

\subsection{Induced voltage and harmonic order}

Induced voltage is directly proportional to flux linkage, revolving the motor understudy at the speed of $1900 \mathrm{rev} / \mathrm{min}$, the back-emf curve is plotted as shown in Fig. 8. It is clear that induced emf is $300 \mathrm{~V}$ with obvious advantage of sinusoidal waveform. Induced emf is the product of flux and speed with an associate constant term as in (9):

Induced emf, $E=k \phi \omega$

Where $\phi$ is flux linkage, $\omega$ is speed of motor, $k$ is constant value

Meanwhile, two kinds of harmonics are space and time. Time harmonics are associated with power system while space is found in electric machine design [34]. Space harmonics are as result of magnetic interacting with various phase windings to create the rotating field. Design improvement will reduce high magnitude level but not be eradicated completely. From Fig. 7, it is obvious that cogging torque of motor is low, Figure 9 illustrates the magnitudes of harmonic order with corresponding low magnitude values.

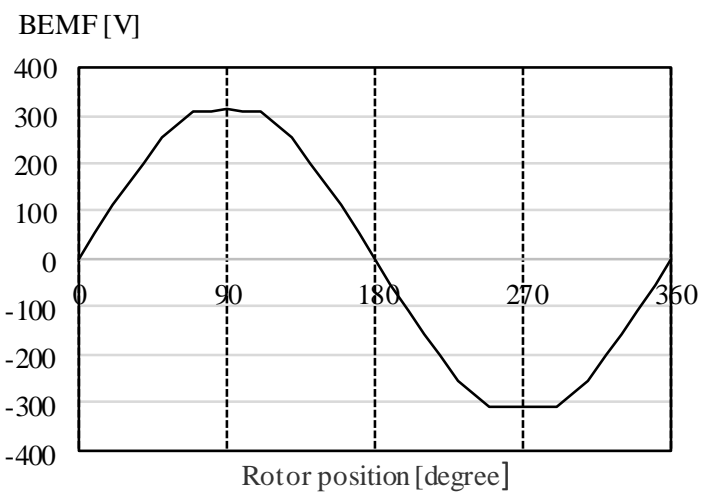

Fig. 7: Cogging torque of Segor-PMFSM at 1900rev/min

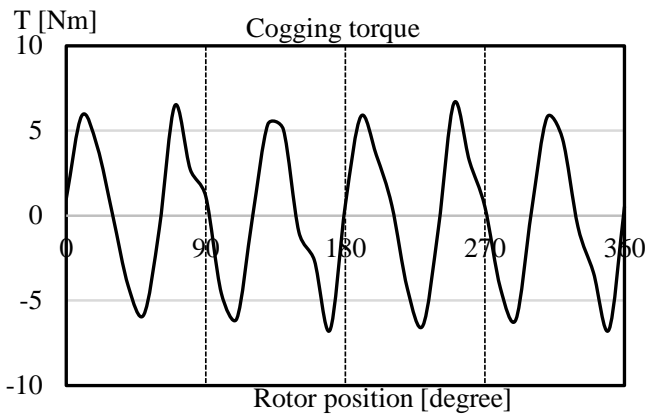

Fig. 8: Induced emf at the maximum speed of $2577 \mathrm{rev} / \mathrm{min}$

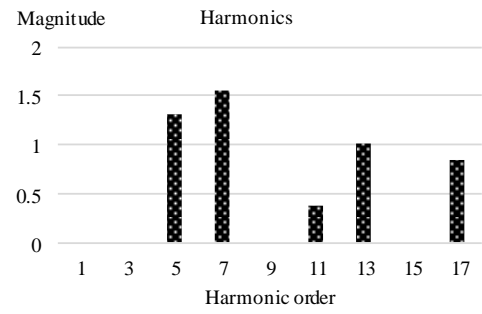

Fig. 9: Magnitudes of order with stator and rotor pole width

\subsection{Steady state torque and power versus speed and motor's losses and efficiency}

Average torque and power versus speed characteristics of the motor understudy Segor-PMFSM, is plotted in Fig. 10. In the plot, it is seen that at the rated speed of $954 \mathrm{rev} / \mathrm{min}$, the maximum torque of $352 \mathrm{Nm}$ was obtained with the maximum power of $35 \mathrm{~kW}$. The speed regions from $0-954 \mathrm{rev} / \mathrm{min}$ witnessed constant torque while beyond it, witnessed constant power. However, when motor is being operated beyond the base speed, torque starts to decrease due to iron loss. Furthermore, while torque decreases, speed in- 
creases and power remains constant throughout motor's operating regions. Furthermore, the motor losses and respective efficiencies for specific operating points 1-8 designated as high torque, medium and low torque regions at different operating speed ranges were calculated including iron loss in all laminated core and copper losses in armature coil respectively.

Accordingly, Segor-PMFSM has short end windings and alternate tooth winding with advantage of less copper loss. However, iron loss was calculated based on 2D-FEA.

The detailed loss analysis and efficiency of Segor-PMFSM is illustrated in Fig. 11. In the chart, $P i$ is the iron loss, $P c$ is the copper loss, and Pout is output power. It can be noticed that when the speed increased, iron loss in stator and rotor also increased. The efficiency achieved at operating point 1 was $77.8 \%$ due to maximum current density. At operating point 2, 77\% efficiency was achieved with highest iron and less copper loss. Meanwhile, efficiency achieved at points 1 - 7 range between $82 \%-89 \%$ respectively while point 8 recorded $78 \%$ higher than point 2 that recorded highest iron loss. This excellent performance is due to gains of using both rotor segment and alternator armature winding.

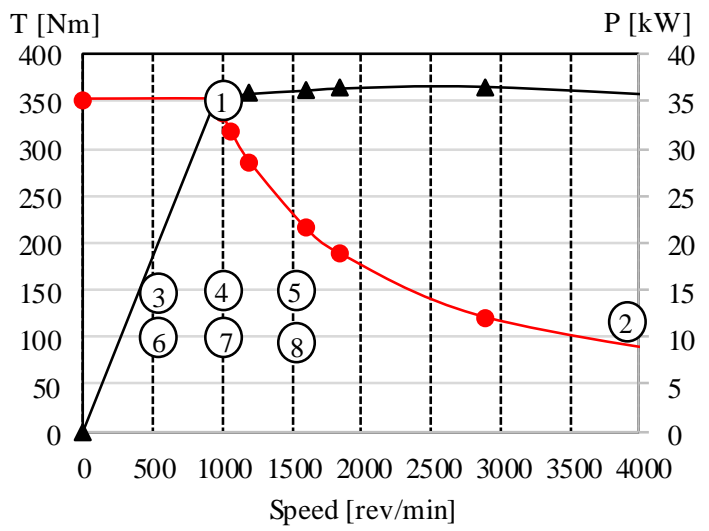

Fig. 10: Steady state torque and power versus speed and operating points.

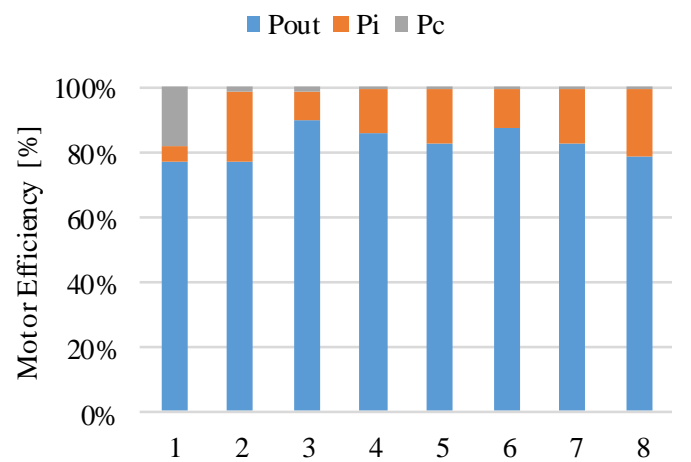

Fig. 11: Motor losses and efficiency for Pspectific operating points in Figure 10

\section{Conclusion}

Evaluation of flux switching motor employing segmented outer rotor with permanent magnet flux source for direct drive application first the first time has been presented. A feasible 24atator and 10 rotor segment is designed for high torque required for the application has been designed using a 2D-FEA JMAG® Studio tool version 14. Armature winding is alternate with $1 \mathrm{~kg}$ of PM in radial magnetization direction. The outer segments are bonded using aluminum without adding excessive load on motor. Performances in terms of magnetic flux linkage and average torque are excellent as torque output is $352 \mathrm{Nm}$ with constant power of $36 \mathrm{~kW}$ throughout entire speed range. Therefore, segmented rotor has presented to dispense low losses while achieving high average torque for direct drive.

\section{Acknowledgement}

This research work was sponsored by Research, \& Management Centre, Universiti Tun Hussein Onn Malaysia (UTHM) and FRGS Grant Vot. 1651 under Ministry of Education, Malaysia.

\section{References}

[1] Haimandan $\mathrm{K} \&$ Ravikumar $\mathrm{S}$, An approach to $\mathrm{CO}_{2}$ capture for mitigating global warming and climate change, An Overview Recent Advances in Space Technology and Climate Change, (2011), pp. 298-2804.

[2] Zhao F, Lee J, Choe Y \& Kwon B, Efficiency optimal design of interior permanent for scooter, International Conference on Electrical Machine and System, IEEE, (2013), pp. 949-953.

[3] Eudy L \& Zuboy, Overview of advanced technology transportation, International Renewable Energy Lab, US, (2004).

[4] Chan, CC, The state of the art of electric, hybrid, and fuel cell vehicles, Proceedings of the IEEE, (2007), pp. 704-718.

[5] Alexander M, Environmental assessment of full electric transportation portfolio, Greenhouse Gas Emission, Electric Power Research Institute, pp. 152, (2015)

[6] Zhu Q, Switched flux permanent magnet machines innovation continues, In Proceeding International Conference on Electrical machines and Systems, (2011), pp. 1-10.

[7] Jenal M, Erwan S, Kumar R, A new switched flux machine employing alternate circumferential and radial permanent magnet for light weight ev, Journal of Magnetics, Vol. 21, no 4, (2016), pp.537-543.

[8] Erwan S. Kosaka T \& Matsui N, Design and analysis of high torque density and high power density hybrid dual excitation switched flux machine for traction drive in hevs, Renewal and Sustainable Energy, (2011), pp. 517-524

[9] Erwan S. Kosaka T \& Matsui N, Design and analysis of high torque density and high power density hybrid dual excitation switched flux machine for traction drive in hevs, Renewal and Sustainable Energy, (2011), pp. 517-524

[10] Jenal M, Erwan S, Khan F \& Haron ZA, A 2-D FEA based design study on salient rotor three-phase permanent magnet flux switching machine with concentrated winding, Applied Mechanics and Materials, Vol. 785, (2015), pp. 274-279.

[11] Kannan S, Novel rotor and stator swapped switched reluctance motor, IEEE International Conference on Power Electronics, Drives and Energy Systems, (2013).

[12] Thomas S, Zhu ZQ \& Jewell GW, Comparison of flux switching and surface mounted permanent magnet generators for aerospace applications, In Proceeding, IET PEMD, (2010), pp. 1-5.

[13] Raminosoa T. Gerada C \& Galea M, Design consideration for a fault tolerant flux switching permanent magnet machine, IEEE Transactions Industrial Electronics, (2011), pp. 2818-2825.

[14] Theodore W, Electrical Machines, Drives and Power Systems, Pearson Education Inc., New Jersey, Sixth Edition, (2006), pp. 235236-

[15] Bhattacharya SK, Electrical Machines, McGraw Hill Education (India) Private Limited, New Delhi, Fourth Edition, (2014), pp. 9 10 .

[16] Hoang E, Lecrivain M \& Gabsi M, A new structure of a switching flux synchronous polyphase machine with hybrid excitation, In Proc. $12^{\text {th }}$ Euro Conference on Power Electronics and Application, (2007), pp. 1-8

[17] Wu S, Song L \& Cui S, Study on improving the performance of permanent magnet wheel motor for electric vehicle application, IEEE Transactions on Magnetics Applications, Vol. 43, (2007), pp. 438-442.

[18] Zulu A, Mecrow BC \& Armstrong M, Permanent magnet flux switching motor employing a segmental rotor, IEEE Transactions on Industry Applications, Vol. 6, (2012), pp. 2259-2267.

[19] Chen XY, Deng ZQ, Wang XL \& Li SX, New design of reluctance motor with segmental rotors, Proc. IET International Conference on Power Electronics and Drives, (2010). 
[20] Erwan S, Khan F \& Ahmad MZ, Investigation of field excitation switched flux motor with segmental rotor, IEEE Conference on Clean Energy and Technology (CEAT), (2013).

[21] Mecrow BC, Bedford TJ, Bennet JW \& Celik T, The use of segmental rotors for 2-phase flux switching motor, $17^{\text {th }}$ Proc. International Conference on Electrical Machines, paper 608, (2006).

[22] Ahmad MZ, Erwan S, Haron ZA \& Kosaka T, Preliminary studies on a new outer rotor permanent magnet flux switching machine with hybrid excitation for direct drive, In Proc. IEEE International Conference on Power and Energy, (2012), pp. 928-933.

[23] Mecrow BC, El-Kharashi, Finch JW \& Jack AG, Segmental rotor switched reluctance motor with single tooth windings, In Electric Power Applications, IEEE Proc. Electrical Power Applications, Vol. 150, Issue 5, (2003), pp. 591-599.

[24] Omar MF, Erwan S, Khan F, Romala GM \& Husin ZA, Comparison between single phase and three-phase fefsm with non- overlap windings and salient rotor, ARPN Journal of Engineering and Applied Sciences, (2013).

[25] Dorrell DG, Andrew MK, Mircea P, Lyndon Evans \& David AS, Comparison of different motor design drives for hybrid electric vehicles, Energy Conversion Congress and Exposition (ECCE) IEEE, (2010), pp. 3352-3359.

[26] Fei W, Patrick CKL,Bing X \& Demin W, Design improvement of outer rotor permanent magnet flux switching machine for direct drive urban electric vehicle propulsion, 39 ${ }^{\text {th }}$ Annual Conf. of the IEEE, Industrial Electronics Society (IECON), (2013), pp. 7319 7324.

[27] Laba A \& Kar N, Outer rotor switched reluctance motor design for in-wheel drive electric bus applications, In Proceeding of the 20th International Conference on Electrical Machines, (2012), pp. 418 423.

[28] Raminosoa T, Hamiti M, Gelea M \& Gerada C, Feasibility and electromagnetic design of direct-drive wheel actuator for green taxiing, Energy Conversion Congress and Exposition (ECCE), (2011), pp. 298-2804.

[29] Ahmad MZ, Haron ZA, Erwan S \& Kosaka T, Design studies on $12 \mathrm{~s}-10 \mathrm{p}$ outer-rotor hefsm for in-wheel drive ev applications, IEEE Conference on Sustainable Utilization and Development in Engineering and Technology, (2013).

[30] Rauch SE \& Johnson LJ, Design principles of flux switch alternators, AIEE, Vol. 74, pt. III, (1955), pp. 1261-1268.

[31] Fei W, Shen J, Wang C \& Luk PCK, Design and analysis of a new outer rotor permanent magnet flux switching machine for electric vehicle propulsion, International Journal for Computation and Mathematics in Electrical and Electronics Engineering, Vol. 30, (2011).

[32] Galea M, Gerada C \& Hamiti T, Design considerations for an outer rotor field wound, flux switching machine, 20th Inter. Conf. on Electrical Machines (ICEM), (2012).

[33] Enwelum IM \& Erwan S, Flux switching permanent magnet motor using segmented outer rotor structure for electric scooter, Indonesian Journal of Electrical Engineering and Computer Science (IJEECS), Vol. 6, (2017), pp. 379-386.

[34] Liang X \& Luy Y, Harmonics analysis in induction motors, Conference on Electrical and Computer Engineering, (2006). 